\title{
Method for describing signal conversion processes in analog electronic systems
}

\author{
Mahmoud Al-Suod ${ }^{1}$, Abdullah Eial Awwad ${ }^{1}$, Alaa Al-Quteimat ${ }^{1}$, Oleksandr Ushkarenko² \\ ${ }^{1}$ Department of Electrical Power Engineering and Mechatronics, Tafila Technical University, At-Tafilah, Jordan \\ ${ }^{2}$ Department of Programmable Electronics, Electrical Engineering and Telecommunications, Admiral Makarov National University of \\ Shipbuilding, Mykolaiv, Ukraine
}

\begin{tabular}{|c|c|}
\hline Article Info & ABSTRACT \\
\hline Article history: & \multirow{10}{*}{$\begin{array}{l}\text { One of the main tasks of information technology is to improve existing and } \\
\text { develop new methods for formal recording of various dynamic logical } \\
\text { operations of analog and digital signal conversion in electronic control } \\
\text { systems, acquisition, and processing of information. The stage of formal } \\
\text { recording of any signal transformation process must be presented in the form } \\
\text { of analytic symbols, the sequence of which must form a fully functional } \\
\text { mathematical model. The improved method of the signals conversion } \\
\text { processes description based on a representation of the mathematical models } \\
\text { of the electronic circuits' components in the grapho-analytical form with the } \\
\text { increased information content allows integrating the developed models of } \\
\text { electronic circuit elements with object-oriented programming language in } \\
\text { the form of functional structures. It opens the way to perform parametric } \\
\text { analysis of circuits and other tasks, related to the modeling of electronic } \\
\text { systems. }\end{array}$} \\
\hline Received Aug 18, 2021 & \\
\hline Revised Dec 1, 2021 & \\
\hline Accepted Jan 6, 2022 & \\
\hline Keywords: & \\
\hline Amplifier & \\
\hline Electronic elements & \\
\hline Functional structure & \\
\hline Grapho-analytical model & \\
\hline Signal conversion analysis & \\
\hline
\end{tabular}

This is an open access article under the $\underline{C C B Y-S A}$ license.

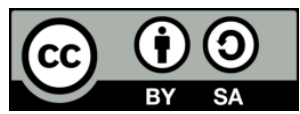

\section{Corresponding Author:}

Abdullah M. Eial Awwad

Department of Electrical Power Engineering and Mechatronics, Tafila Technical University

New Hauway Street 179, At-Tafilah, 66110, Jordan

Email: abdullah.awad@ttu.edu.jo

\section{INTRODUCTION}

Modern electronic systems are mostly digital due to the advantages of digital systems over analog ones. At the same time, analog subsystems are often used in such systems, especially in signal processing channels before their digitization, in audio equipment, power supply systems, and many others. Each of these systems is characterized by a variety of processes for converting continuously variable signals. Any formalized process in its representing includes heterogeneous signal conversion processes. They can be presented in the form of schemes, algorithms, equations or functional blocks, for example, in MATLAB/Simulink [1]. Therefore, for each transformation process, its own method of formal description has been developed, which has led to the emergence of a large number of methods for analyzing signals and systems in each of the various areas of electronics. Since information technology is associated with processes, collecting, storing, processing, disseminating information, and implementing, e.g. processes and methods. We can say that they are "materialized carriers" of various information, and the carrier itself that exists is a formalized record of this information [2]. Systems analysis points to the fact that signal processing systems, in this case analog, must be designed according to certain principles. Therefore, the urgent task is to create a mathematical model that can combine the methods of describing signal conversion processes (SCP) with elements of different nature.

Therefore, one of the main tasks of information technology, as noted in [3]-[5], is the improvement of existing methods and the development of a new approach for the formal recording of different logical and 
dynamic operations of analog and digital signal conversion in electronic control systems, information collection, and processing. The fact that the stage of the formal recording of any SCP should be presented in the form of analytical symbols, which in its sequence should form a fully functional mathematical model [5], [6]. In this case, the main quality of the final model of analog signals is to minimize the verbal description of its content [7]. In addition, the development of grapho-analytical solutions as applied to electronic systems of analog data processing will allow analyzing the processes of arguments transformation at the informationquality level. Also there is the need to improve the quality of formalized analysis of signal conversion. The result of the analysis can be an assessment of the speed of one or another project solution. This leads to improving the structures and methods of data processing in analog electronic systems. The advantages and disadvantages of different methods to solve the optimization problems are introduced in [8]. In detail, one of the problems with optimization algorithms is to limit the applicability of the given method, and this is due to the characteristics of the processes that occur in systems of a different physical nature. The lack of a unified mathematical model for describing processes in systems of different physical nature necessitates research in this direction. This was also confirmed by the study [9], which indicated that the analysis of the system at different levels of decomposition requires the use of different methods. One of the methods of analyzing electronic systems is the method of creating algorithms and topology diagrams. But these methods do not allow the implementation of these actions at a formalized level. The process of assembling high-speed elements that performs arithmetic operations is considered [10]. Structural diagram is used to describe a system. At the same time, there is no formal description of data transformation processes, which makes it difficult to understand the principles of information transformation that the system performs. This is due to the fact that they are not functionally complete mathematical models that have an analytical form of writing. In addition, they are also not grapho-analytical expressions of the analyzed logical-dynamic process of transforming input signals.

One of the possible ways to improve the quality of analysis of dynamic logical operations while increasing the information content is analytical and grapho-analytical methods. These methods are successfully used in the design and analysis of hierarchical software systems, as described in [11]. Based on that, it becomes possible to analyze the correctness of conversion processes in different control systems. However, the methods considered in [11] are not applicable to the analysis of analog electronic systems. Since the analytical form of the description of the system is necessary for the subsequent formal improvement of a particular process, it is necessary to make the mathematical model of the electronic system easy to write and provide it with the maximum information content. The research results presented in [12], [13] confirm the advantage of using formal methods and models developed in the analysis and improvement of control systems. Nevertheless, these methods need development, taking into account the peculiarities of the performance and methods of displaying information in analog electronic systems. Thus, the analysis of the recent researches has shown that currently there is unrealized potential for the development methods to analyze data conversion processes occurring in analog electronic systems. In detail, the problem of the analytical description of the processes of continuous arguments transformation with the aim of its optimizing remains unresolved, which confirms the relevance of the chosen direction of research.

The aim of this paper is to improve the method of building mathematical models of electronic circuit components for their presentation in graph-analytical form with increased information content for their further integration with object-oriented programming language in the form of functional structures and solving problems of analysis and modeling of electronic systems. To achieve the goal set in the work it is necessary to solve the following tasks:

- Analyze the classical methods of forming mathematical models of electronic circuits and identify possible ways to improve them for the formation of mathematical models with "analog" form of information, which are based on the functional structures of the elements of electronic circuits.

- Propose notation and develop functional structures of resistor function $f(R)$, operational amplifier $f(\mathrm{OA})$, semiconductor functions $f(n-p-n)$ and $f(p-n-p)$, which can be written in the form of graph-analytical expressions, and at another level of understanding carry information on the logic of signal conversion in electronic systems.

- To develop software in which the developed functional structures of elements of various electronic circuits (amplifiers and active filters built on the basis of the operational amplifier, the amplifier cascade with the general emitter) and methods of their parametric analysis for research of influence of external factors on separate indicators and parameters of electronic systems that characterize the processes of their functioning.

The developed circuit solutions of functional structures for the transformation of arguments with the "analog" form of information presentation do not belong to the category of analytical form of recording specific logical-dynamic processes. On their basis, not only various arithmetic transformations can be performed, such as adding and multiplying arguments, but also procedures for controlling and managing 
various technological processes. And if for digital argument structures the analytical form of record of various logical functions was formed and rules of transformation of their functional structures were formed [14], [15], and for analog arguments it is also necessary to form the analytical form of record of various functional structures in which the basic elements are functional structures of operating amplifier $f(\mathrm{OA})$, resistor $f(R)$ and semiconductor elements $f(n-p-n)$ and $f(p-n-p)$. It should be added that the method of synthesis of grapho-analytical models of logical-dynamic processes of signal conversion in digital systems, and the corresponding notation, was first developed and proposed by a talented Ukrainian inventor L. P. Petrenko.

\section{RESEARCH METHOD}

From the analysis of the conditional graphic notation of the operational amplifier (OA) and its real content, it follows that if you use only analytical symbols, it can be written in the form of a graph-analytical expression presented in Figure 1. The graphic symbol is written as a system symbol (\}) with input and output functional connections $f(\rightarrow)$. In this case, the functional input links are specified by additional symbols "+" and "-", and have a unique meaning, which is accepted when writing in the graphic image of OA. A similar result can be obtained for other functional structures (resistor, capacitor, diode, transistor). The functional structure $f(\mathrm{OA})$ with negative feedback can be written in the form of a grapho-analytical expression in Figure 2.

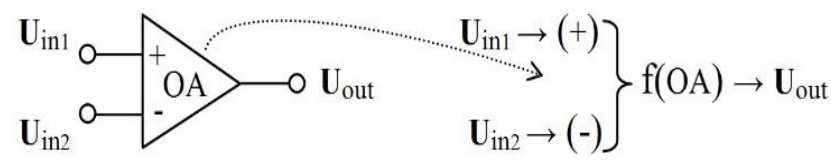

Figure 1. Representation of the operational amplifier in grapho-analytical form

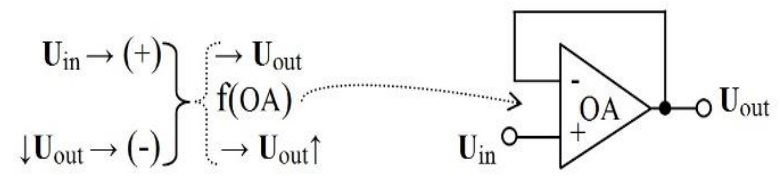

Figure 2. Grapho-analytical model of the functional structure of OA with negative feedback

From the comparative analysis of the analytical expression of the functional structure $f(\mathrm{OA})$ with negative feedback and its graphical record, it follows that they are equivalent in their content, because as feedback in the analytical expression recorded the resulting argument $U_{\text {out }} \uparrow$ with interrupted functional connection, and the same argument $\downarrow U_{\text {out }}$ at the conditionally negative input of the system of functional structure $f(\mathrm{OA})$. A variant of the functional structure $f(\mathrm{OA})$ with adjustable negative feedback can be represented as a grapho-analytical expression presented in Figure 3. The functional structure of the inverting adder, made using $f(\mathrm{OA})$, can be written in the form of a grapho-analytical expression presented in Figure 4 .

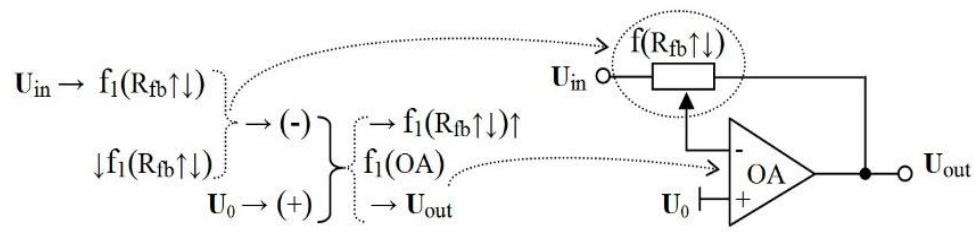

Figure 3. Grapho-analytical model of the functional structure of the amplifier

A feature of the model is the presence of additional positive (+) and conditionally negative (-) input connections of the functional structure $f(\mathrm{OA})$. These additional connections of the functional structure $f(\mathrm{OA})$ correspond to the combination of the currents of the resistor functions. The logic of formation of the 
functional structure of the inverting adder does not differ significantly from the logic of formation of the considered grapho-analytical model.

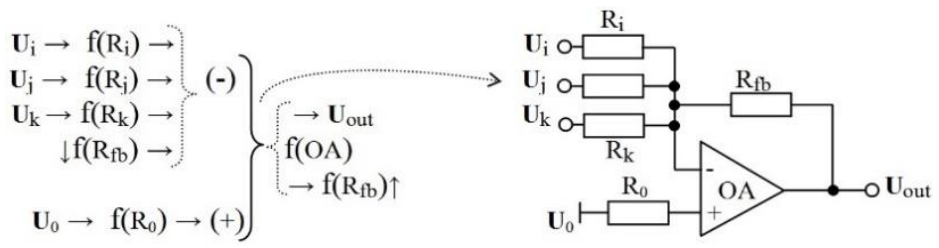

Figure 4. Grapho-analytical model of inverting adder

This approach can be used to write the functional structures $f(R)$ of conductors that form the current $I_{R}$ between the arguments $U_{d}$ or $-U_{d}$, which are the structures of the conversion of external voltage in the form of arguments $\pm U_{d}$. Therefore, for the correct interpretation of the logical-dynamic processes of current conversion in its structure, they must be written in the form of analytical expressions. For example, the functional structure of the resistor function $f(R)$ can be written in the form of grapho-analytical expressions presented in Figure 5.
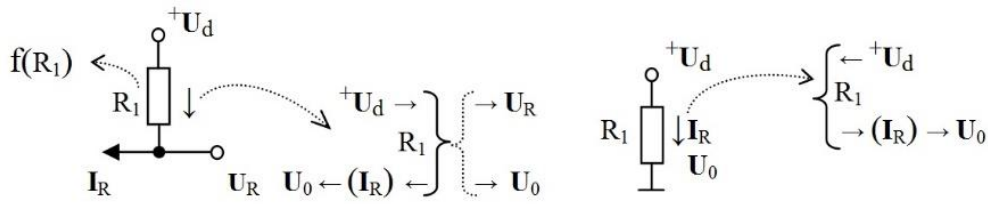

Figure 5. Grapho-analytical models of the functional structure of the resistor

The current argument " $I_{R}$ " is an intermediate argument of the functional structure $f_{1}(R)$, which, according to Ohm's algebraic law to form the argument of the potential difference $U_{\mathrm{R}}$ performs the functional action of multiplying $f$ (multiplication) of the current " $I_{R}$ " by the functional structure $f_{1}(R)$. In this situation, the current " $I_{R}$ " is essentially the value of the argument of the potential difference $U_{R}$, which depends on the specific value of the functional structure $f_{1}(R)$. If we write the analytical expression of the mathematical model that implements the procedure of forming the argument of the potential difference $U_{R}$ in the form of a grapho-analytical expression (Figure 6), then its analysis shows that using the functional structure of the adder $f_{1}(\Sigma)$ ("voltmeter") form the argument of the potential difference $\left({ }^{+} U_{R 0} \& U_{0}\right) \rightarrow U_{R 0}$, which is formed using the functional structure $f_{0}(R)$.

It should be noted that the additionally introduced functional structure $f_{1}\left(R_{\max }\right)$ performs the task not of generating the current " $I_{R}$ ", but the coordination of the possible dynamic range of change of the argument of the potential difference ${ }^{+} U_{\mathrm{d}} \rightarrow{ }^{+} U_{0}$, which can be formed in the functional structure $f_{1}(R)$ and a fixed value of the possible dynamic range of the functional structure of the adder $f_{1}(\Sigma)$. If we write another algebraic expression of Ohm's law in the form of an algebraic expression presented in Figure 7(a), which performs the function $f$ (division) of the value of the voltage argument ${ }^{+} U_{\mathrm{d}}$ on the value of the functional structure $f_{1}(R)$, the resulting argument will not be the current " $I_{R}$ ", and the value of the argument of the potential difference $\Delta U_{R}$. The semiconductor functions $f(n-p-n)$ and $f(p-n-p) n-p-n$ and $p-n-p$ structures can be written in the form of analytical expressions presented in Figure 8 respectively.

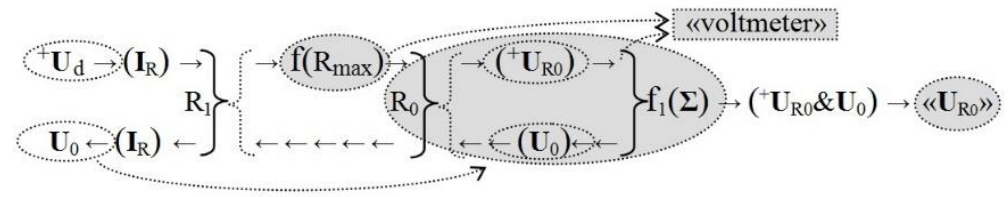

Figure 6. The procedure for forming the argument of the potential difference 


$$
\left({ }^{+} \mathbf{U}_{\mathrm{n}} \& \mathbf{U}_{0}\right) \rightarrow{ }^{+} \mathbf{U}_{\mathrm{m}} \mathrm{f}(\text { division }) \mathrm{R}_{1} \rightarrow \mathbf{I}_{\mathrm{R}}
$$

(a)

$$
\begin{aligned}
& \rightarrow \text { «Ohm's algebraic law» } \\
& \mathbf{I}_{\mathrm{R}} \rightarrow \mathbf{I}_{\mathrm{R}} \mathrm{f}\left(\text { multiplication) } \mathrm{R}_{1} \rightarrow \mathbf{U}_{\mathrm{R}}\right.
\end{aligned}
$$

(b)

Figure 7. Presentation of the procedure for forming the potential difference (a) voltage dependent and (b) current dependent

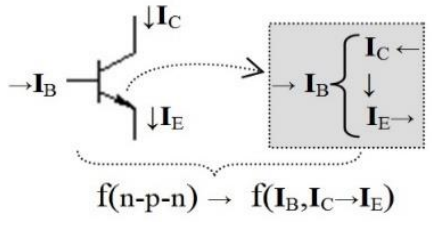

(a)

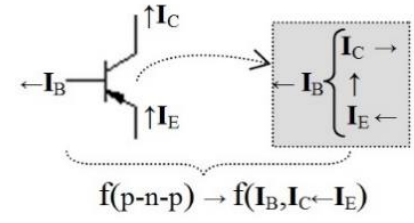

(b)

Figure 8. Representation of (a) $f(n-p-n)$ and (b) $f(p-n-p)$ functional structures

The symbols $n-p-n$ and $p-n-p$ are formalized to the symbols $(\downarrow)-\mathrm{n}$-conductivity and $(\uparrow)-\mathrm{p}$ conductivity between the functional connections of the collector current arguments $I_{C}$ and the emitter current argument $I_{E}$ in their system ( $\}$ ) and are completely equivalent to the graphical representation of transistors of corresponding conductivity. But if we take into account that in the schematics the currents $I_{C}, I_{E}$ and base current $I_{B}$ are usually not written, the proposed record of semiconductor functions in the form of analytical structure $f\left(I_{B}, I_{C} \rightarrow I_{E}\right)$ and $f\left(I_{B}, I_{C} \leftarrow I_{E}\right)$ contains the information about currents. This record is more consistent with the process implemented in semiconductor $n-p-n$ and $p-n-p$ structures when activating the arguments of the current $I_{C}$ and $I_{E}$ on one side of the system, and this activation is directly related to changing the argument of the base current $I_{B}$ on the other side of semiconductor functions $f\left(I_{B}, I_{C} \rightarrow I_{E}\right)$ and $f\left(I_{B}, I_{C} \leftarrow I_{E}\right)$. The functional input connections $(\downarrow)$ and $(\uparrow)$ are the arguments of currents $I_{C}, I_{E}$, and the conductivity symbol $(\downarrow)$ $-n$ or $(\uparrow)-p$, form a sequential structure of the transformation of current arguments in the structure of functions $f\left(I_{B}, I_{C} \rightarrow I_{E}\right)$ and $f\left(I_{B}, I_{C} \leftarrow I_{E}\right)$.

The symbol "R" in the analytical expression in Figure 7(b) of the "Ohm's Law", corresponds to the functional structure of $n-p-n$ transistor, Figure 8(a), and $p-n-p$ transistor, Figure 8(b). Therefore, in order to form a mathematical model of the Ohm's law in its structural and functional record of the analog logicaldynamic process of transformation of the input argument $U_{i n}$, it is necessary to combine the analytical expressions presented in Figure 5 and Figure 9, in the general functional structure presented in Figure 9.

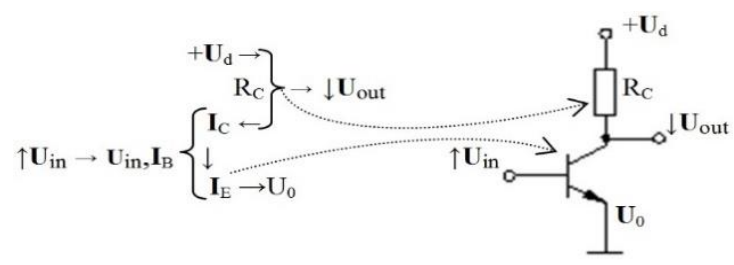

Figure 9. Correspondence between the analytical model and its circuit implementation

In Figure 9 there is marked $\uparrow U_{\text {in }}$ - input voltage argument, and $\downarrow U_{\text {out }}$ - converted voltage argument. From the analysis of the grapho-analytical expression in Figure 9, it follows that the analytical form of the record and the circuit implementation of the transistor amplifier are essentially completely equivalent, and are the process of converting the input argument $\uparrow U_{\text {in }}$ with a small level of analog signal into the resulting output argument $\downarrow U_{\text {out }}$ with an increased level of analog signal, based on semiconductor $f\left(I_{B}, I_{C} \rightarrow I_{E}\right)$. From the analysis it also follows that on the one hand, any analog logical-dynamic process of argument transformation, which is formed at the level of the schematic diagram, can be written as a mathematical model at the analytical level. On the other hand, combining the above expressions in the grapho-analytical structure (Figure 10), we can say that the mathematical model of analog logical-dynamic process of argument transformation at the structural-functional level, and in its circuit implementation is completely equivalent to the Ohm's law. 


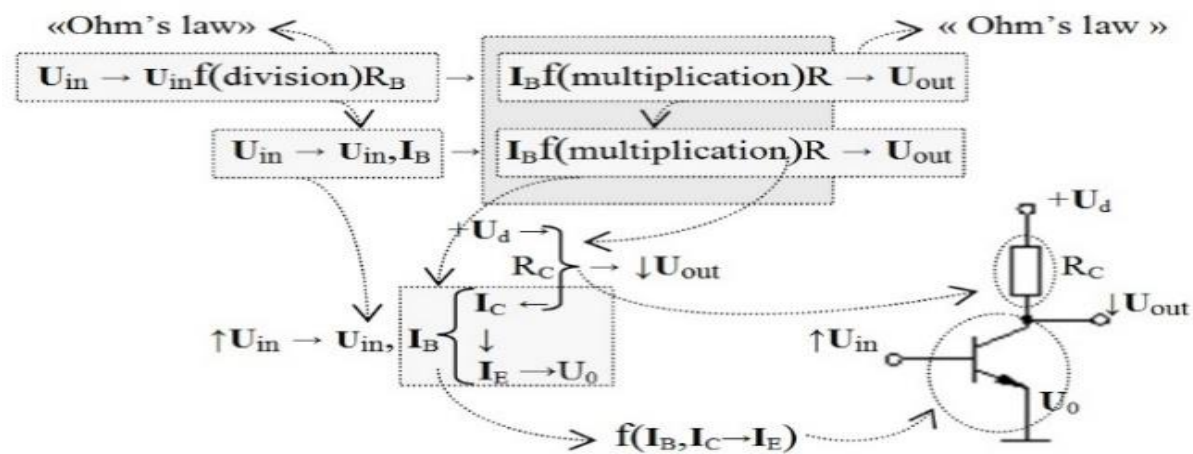

Figure 10. Mathematical model of analog logical-dynamic process of argument transformation at the structural-functional level

The functional semiconductor structure " $f\left(I_{B}, I_{C} \rightarrow I_{E}\right) \& f(R)$ " essentially performs the procedure of multiplying $f$ (multiplication) of the input current argument $U_{i n} \rightarrow U_{i n}, I_{B} \rightarrow$ "I $I_{B}$ " with the formation of the transformed voltage argument $U_{\text {out }}$. The peculiarity of the analytical form of the record (Figure 10) is that it clearly reflects the logic of formation of the transformed argument $\downarrow U_{\text {out }}$ at the level of arguments and functions, and this logic is written between two symbols of the system. Another feature of this analytical form of writing is that to clarify the functional relationship of arguments, you can write a grapho-analytical structure (Figure 11), which at another level carries information about the interdependent logic of argument transformation.

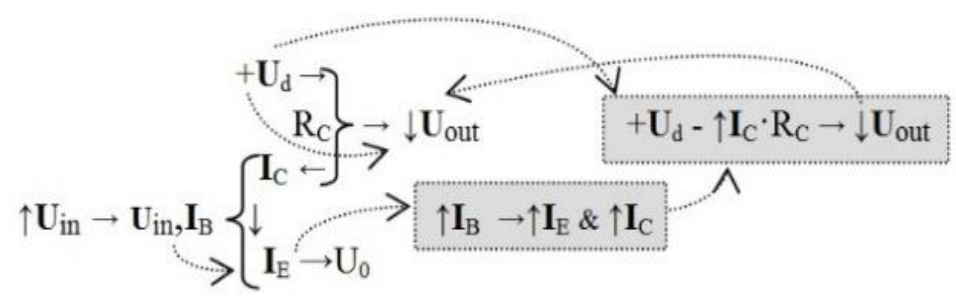

Figure 11. Functional relationship of arguments in the model

The functional structure with the resistor function $f\left(R_{C}\right)$ in the original grapho-analytical expression can also be written in accordance with its algebraic properties in the form of a sequential functional structure $f(--)$ :

$$
f\left(R_{C}\right) \rightarrow f\left(R_{1} \& R_{2}\right) .
$$

Further, a functional structure with a resistor function $f\left(R_{2}\right)$ can be transferred by its functional connection, and form a useful property in the adjusted expression. In the mathematical model (Figure 11) it is possible to transfer the functional structure with the resistor function $f\left(\mathrm{R}_{2}\right)$ according to the functional connections of the structure of the semiconductor function $f\left(I_{C}, I_{B}\right)$, and this procedure can be written as a grapho-analytical structure presented in Figure 12.

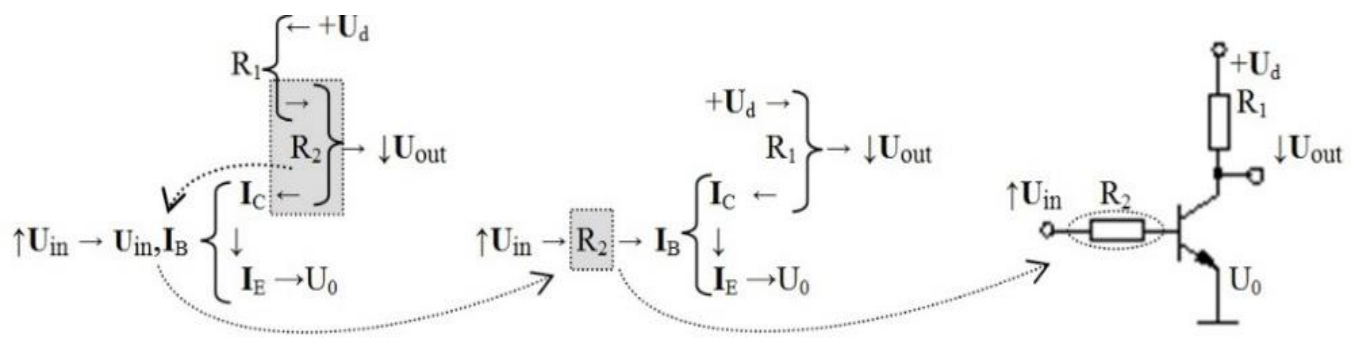

Figure 12. Transfer of the resistor function $f\left(R_{2}\right)$ by functional connections of the structure of the semiconductor function $f\left(I_{C}, I_{B}\right)$ 
From the analysis of the given grapho-analytical models of systems of structural and functional signal conversion in electronic systems, it follows that in the synthesis of mathematical models of logicaldynamic processes of transformation of input arguments the procedure of additional introduction of functional structures that do not lead to non-equivalent transformation process was performed. But this introduction of additional functional structures has significantly expanded both the functional content of the logical-dynamic process of argument transformation, and structural and functional capabilities in the synthesis of a particular mathematical model. It should be noted that to form a useful property of the system, the functional structures must be moved by their functional relationships. The procedure for transferring only the resistor function $f\left(R_{2}\right)$ according to the functional connections of the structure of the semiconductor function $f\left(I_{C}, I_{E}\right)$ is presented in Figure 13 .

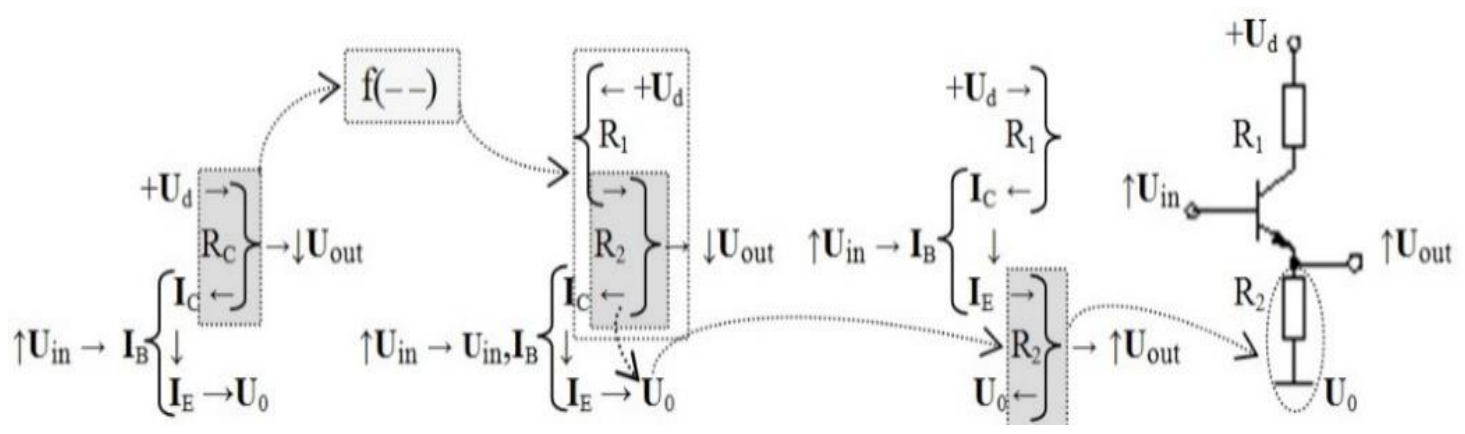

Figure 13. Transfer of resistor function $f\left(\mathrm{R}_{2}\right)$ by functional connections of semiconductor function structure

$$
f\left(I_{C}, I_{E}\right)
$$

\section{RESULTS AND DISCUSSION}

The method for describing signal conversion processes in analog electronic systems, considered in this paper, is a further development of the previous studies carried out by the authors, the results of which were published in [3]-[5], [13], [14]. The approach proposed by the authors expands the use of the method of synthesis of logical-dynamic processes mathematical models of control and data acquisition systems for its use in relation to analog electronic systems. By analogy with [14], [16], rules for describing electronic components and continuously variable signals were developed, which made it possible to apply the method to analyze systems of various physical nature, thereby partially solving the problems described in [8], [9], [17][21]. The versatility of the used mathematical apparatus also makes it possible to describe processes in electronic systems with varying degrees of detail. This opens up the possibility of a deep understanding of the processes occurring in electronic systems, and the proposed method serves as a tool for choosing the optimal circuit design in each specific case. The developed graphical-analytical models of electronic circuits are a convenient tool for their analysis. These models were integrated by the authors with an object-oriented programming language, which made it possible to develop appropriate software for parametric analysis of active filters, as well as for calculating and analyzing the position of the operating point of the amplifying stage, as shown in subsection 3.1 and 3.2.

\subsection{Software for parametric analysis of active filters}

One of the main stages of system design, in particular electronic systems, is parametric analysis. The parameter of the object is a value that characterizes some property of the object or the mode of its operation [22]. In the context of electronic systems, the object is an electronic circuit. The procedure of parametric analysis is to study the designed electronic system, which aims to obtain useful information about its properties. The description of the electronic system, in the General case, is a mathematical model of the system, which can be represented as a system of equations or in another form [23]. Non-stationary characteristics and parameters of individual elements that are part of the electronic system affect the characteristics of the entire system and can lead to deterioration of the quality of its operation under the influence of external factors. Therefore, the purpose of parametric analysis is to verify the performance of the electronic system when changing the parameters of its elements in a certain range, which may be due to external factors (e.g., temperature). The specificity of the task of parametric analysis of electronic systems is the use of special methods, appropriate structures and technical implementation of such systems. The transfer function of the second-order low-frequency filter, implemented based on OA according to the Sallen-Key scheme, has the form [24], [25]: 


$$
A(s)=\frac{1}{1+\omega_{c} C_{1}\left(R_{1}+R_{2}\right) p+\omega_{c}^{2} R_{1} R_{2} C_{1} C_{2} p^{2}}
$$

The coefficients $a_{1}$ and $b_{1}$ are defined by the expressions:

$$
\begin{aligned}
& A_{0}=1 \\
& a_{1}=\omega_{c} C_{1}\left(R_{1}+R_{2}\right) \\
& b_{1}=\omega_{c}^{2} R_{1} R_{2} C_{1} C_{2}
\end{aligned}
$$

In Figure 14 the appearance of the dialog box of the developed software designed to analyze the frequency characteristics of active low-pass filters of the second order is shown. To perform parametric analysis of the circuit and study the effect of temperature change on the characteristics of the filter due to changes in the resistance of the resistors, the temperature resistance coefficients $\alpha 1$ and $\alpha 2$ are used (for the first and second resistors, respectively).

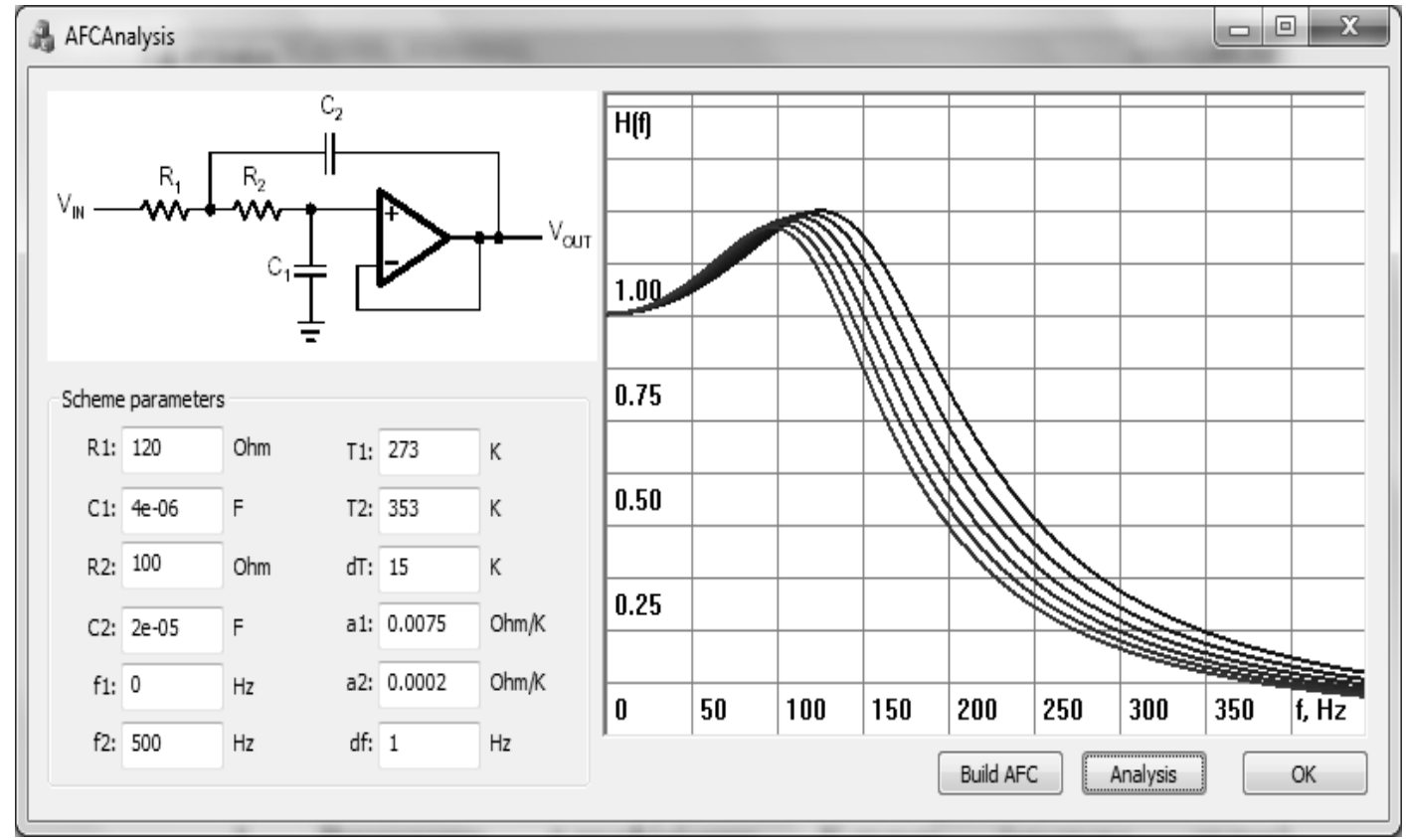

Figure 14. The interface of software tools for constructing the frequency response characteristics of active low-pass filter

In this example, the values of the temperature coefficients of resistance are different, and when the temperature changes along with the frequency response characteristics shift in the direction of low frequencies also decreases the amount of non-uniformity in the bandwidth of the filter. It is possible that at certain values of resistor resistances and resistance temperature coefficients, a change in ambient temperature will lead to the conversion of the chebyshev filter into a butterworth filter.

\subsection{Software for calculating and analyzing nonlinear circuits}

From the analysis shown in Figure 13 grapho-analytical structures, it follows that the procedure of their transfer is essentially equivalent to those actions that are performed when transforming the structure of algebraic expressions. It should be noted that in this situation, the transfer is both complete and incomplete, because one of the functional connections of the resistor function $f\left(\mathrm{R}_{2}\right)$ using the semiconductor function $f$ $\left(I_{C}, I_{B}\right)$ is a functional connection of the resistor function $f\left(\mathrm{R}_{1}\right)$. In Figure 15 one of the possible implementations of the interface of the software for calculation and analysis of a transistor amplifier with a common emitter is shown. The development of information technologies and their close integration with electronics have made it possible to implement the tasks of designing and analyzing systems at a qualitatively new level, using software that has a graphical user interface. The graphical interface of software for 
parametric analysis of electronic systems is a tool designed to facilitate the organization of research, understanding the results of the analysis and their transfer for use in external applications (Matlab, Mathcad.). The development of such tools is the end result of the implementation of the presented results.

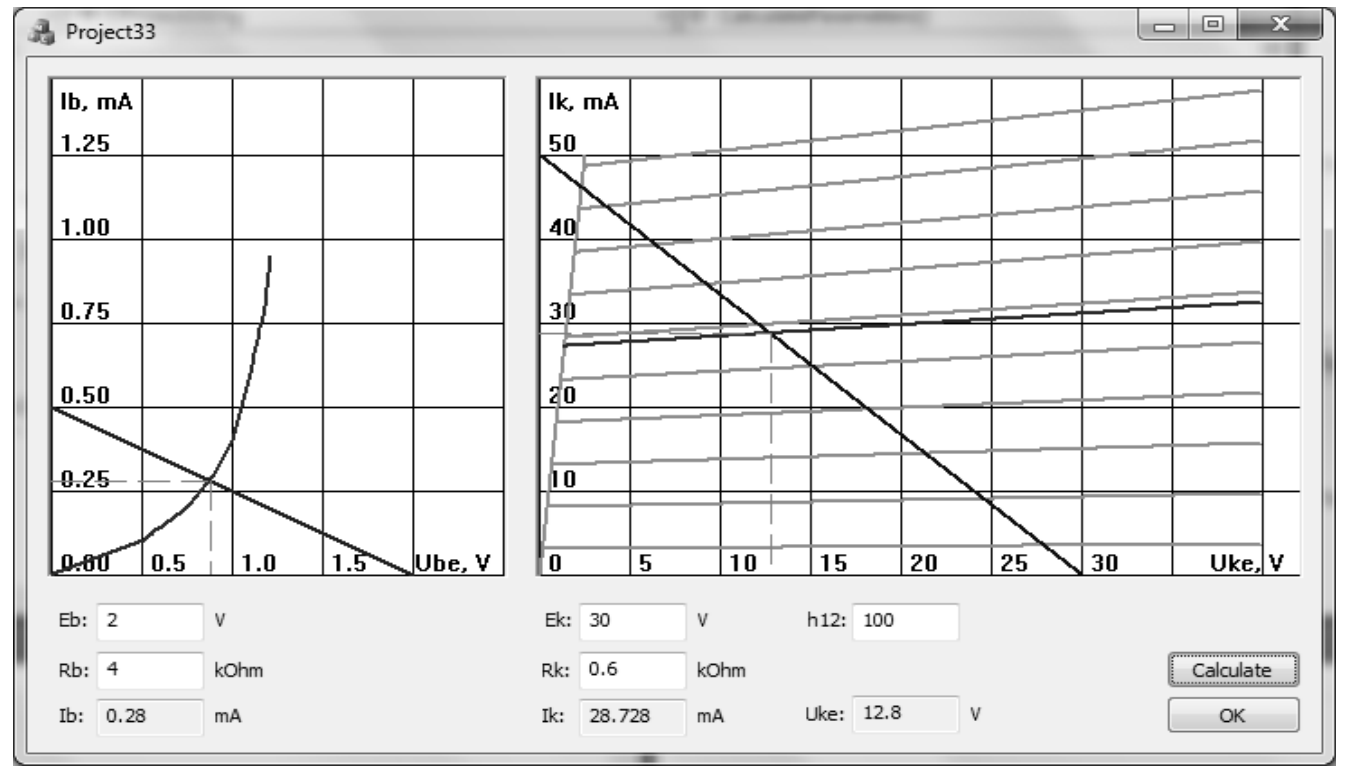

Figure 15. The user dialog of software for calculation and analysis of transistor amplifier

\section{CONCLUSION}

In the course of the research, the following scientific results were obtained: (1) based on the analysis of classical methods of forming mathematical models of electronic circuits, it is established that they have reserves for improvement in terms of forming mathematical models of analog electronic circuits, which are based on functional structures of operational amplifier, $n-p-n$ and $p-n-p$ structures, (2) functional structures of resistor function $f(\mathrm{R})$, semiconductor functions $f(n-p-n)$ and $f(p-n-p)$ are developed, which are presented in the form of grapho-analytical expressions and contain information about the processes of signal conversion occurring in them, (3)developed tools in the form of software to automate the processes of parametric analysis of electronic circuits, which were implemented using object-oriented programming language $\mathrm{C}++$. The software has an intuitive user interface and is relatively easy to use compared to known environments for modeling electronic systems, which is expressed in the need to specify a minimum set of values to perform parametric analysis of the electronic circuit.

The scientific novelty of the obtained results is that the method for describing signal conversion processes in analog electronic systems was improved, based on the use of mathematical models of electronic components, presented in grapho-analytical form with increased information content, which allowed to integrate component models with object-oriented programming language in the form of functional structures, and to simplify the software implementation of methods of electronic circuits parametric analysis to assess the impact of external factors on the characteristics of the system, The practical significance of the obtained results is that the proposed approach to the analysis of electronic circuits using information technology, on the one hand, allows a deeper understanding of the processes of signal conversion occurring in electronic systems, and on the other-contributes to the systematic formation of training, in which they will have a system of knowledge and skills in relevant areas of electronics and information technology, which in today's world are inextricably linked. In addition, the developed software is a tool that can be useful to an electronics engineer to perform calculations and analysis at the stage of design and manufacture of electronic systems for various purposes.

\section{REFERENCES}

[1] H. Le-Huy, "Modeling and simulation of electrical drives using Matlab/Simulink and Power System Blockset," The 27th Annual Conference of the IEEE Industrial Electronics Society (IECON'01), Denver/Colorado, 2016, vol. 3, pp. 1603-1611, doi: 10.1109/IECON.2001.975530. 
[2] Y. I. Bobalo, R. I. Zheliak, M. D. Kiselychnyk, Z. O. Kolodii, B. A. Mandzii and V. M. Yakubenko, Matematychni modeli ta metody analizu elektronnykh kil. Lviv: Vydavnytstvo Lvivskoi politekhniky, 2013.

[3] V. M. Riabenkyi and A. O. Ushkarenko, "Metod syntezu matematychnykh modelei lohiko-dynamichnykh protsesiv kontroliu ta keruvannia," Tekhnichna elektrodynamika. Tem. vypusk, vol. 2, pp. 121-125, 2011.

[4] V. M. Riabenkyi and A. O. Ushkarenko, "Metod strukturnogo sinteza i analiza modelej ustrojstv avtonomnoj ehlektroehnergetiki, " Tekhnichna elektrodinamika. Tem. vipusk, vol. 4, pp. 130-133, 2012.

[5] V. M. Riabenkyi and A. O. Ushkarenko, "Analiticheskij metod opisaniya interfejsa avtomatizirovannogo rabochego mesta operatora ehlektroehnergeticheskoj sistemy," in Suchasni informacijni ta innovacijni tekhnologï na transporti (MINTT-2014), Kherson, Ukraine, May 27-29, 2014, pp. 215-218.

[6] O. O. Ushkarenko, "Zasoby analizu protsesiv peretvorennia informatsii v systemakh upravlinnia," in Informatsiini tekhnolohii ta kompiuterne modeliuvannia: materialy statei Mizhnarodnoi naukovo-praktychnoi konferentsii, Ivano-Frankivsk, Ukraine, May 2328, 2016, pp. 10-11.

[7] A. O. Ushkarenko, "Formalizaciya procedury preobrazovaniya informacionnykh argumentov v sistemakh upravleniya," in Elektromekhanichni ta energetichni sistemi. Metodi modelyuvannya ta optimizaciï, zbirnik naukovikh prac KHVI Mizhnarodnoï naukovo-tekhnichnoi konferencii molodikh uchenikh i specialistiv, Kremenchuk, Ukraine, Apr 12-13, 2018, pp. 71-72.

[8] Y. L. Xiaoxi, L. Zhewen, S. Mingwei, L. Jing, F. and Liang Z., "A Survey on Particle Swarm Optimization Algorithms for Multimodal Function Optimization," Journal of software, vol. 6, no. 12, pp. 2449-2455, 2011, doi: 10.4304/jsw.6.12.2449-2455

[9] Yudong Z., Shuihua W. and J. Genlin, "A Comprehensive Survey on Particle Swarm Optimization Algorithm and Its Applications," Mathematical Problems in Engineering, vol. 2015, ID. 931256, pp. 1-38, 2015.

[10] G. M. Ramana, C. Senthilpari, P. Velrajkumar and T. S. Lim, "A Novel Design of Multiplexer Based Full-Adder Cell for Power and Propagation Delay Optimizations," Journal of Engineering Science and Technology, vol. 8, no. 6, pp. 764-777, 2013.

[11] B. Aminof, F. Mogavero and A. Murano, "Synthesis of hierarchical systems," Formal Aspects of Component Software, vol. 83, pp. 42-60, 2016, doi: 10.1016/j.scico.2013.07.001.

[12] V. M. Ryabenkiy and A. O. Ushkarenko A. O., "Formalnoye opisanie elementov avtomatizirovannogo rabochego mesta operatora electroenergeticheskoi sistemy," Naukivyi vistnyk Khersonskiy derjavniy morskiy akademiyi, vol. 1, no. 1, pp. 43-50, 2014.

[13] M. S. A. Mahmoud and A. O. Ushkarenko, "Analytical Representation of Control Processes of Induction Motor and Synchronous Generator in Power Plants," Jordan Journal of Electrical Engineering, vol. 2, no. 4, pp. 278-288, 2016.

[14] M. M. Al-Suod, A. Ushkarenko and L. Petrenko, "Analysis of logical-dynamic conversion processes in arithmetic devices of digital control systems," Eastern European Journal of enterprise technologies, vol. 6, no. 4, 90, pp. 28-34, 2017.

[15] G. F. Krivulya, V. M. Riabenkyi and L. P. Petrenko, "Metodika formirovaniya matematicheskoj modeli summatora v formate troichnoj sistemy schisleniya," Avtomatizirovannye sistemy upravleniya i pribory avtomatiki, vol. 145, pp. 121-133, 2008.

[16] D. I. Popov, "Optimization of digital signal processing systems," University Proceedings. Volga Region. Technical Sciences, no. 1 (41), pp. 96-104, 2017.

[17] A. E. Awwad, A. A. Quteimat, M. A. Suod, O. O Ushkarenko and A. A. Hawamleh, "Improving the accuracy of the active power load sharing in paralleled generators in the presence of drive motors shaft speed instability," International Journal of Electronics and Telecommunications, vol. 67, no. 3, pp. 371-377, 2021.

[18] M. Al-Suod, "Development of hardware and software for calculation and monitoring of the unbalance factor in three phase voltage system," Eastern European Journal of Enterprise Technologies, vol. 1, no. 9, pp. 39-45, 2018.

[19] A. E. Said and A. M E. Awwad, "A comparative study of performance of AC and DC electric drive control systems with variable moment of inertia'," Bulletin of Electrical Engineering and Informatics, vol. 10, no. 2, pp. 588-597, 2021, doi: 10.11591/eei.v10i2.2768.

[20] M. Alaa, M. Mahmoud, M. Abdullah, A. H. Atia, Z. Mahmoud, O. Ushkarenko and O. Dorohan, "Research of the Data Exchange Processes during the Automated Control of Autonomous Electric Power Systems," IOSR Journal of Electrical and Electronics Engineering, vol. 15, no. 2, pp. 48-52, 2020.

[21] M. S. Mahmoud, M. Abdullah, S. Mohammad, M Alaa, and O. Ushkarenko, "Optimization of the Speed Controller in Gas Diesel Device Including in the Autonomous Electric Power System," IOSR Journal of Electrical and Electronics Engineering, vol. 14, no. 4, pp. 42-48, 2019.

[22] P. Heena and M. VIishal, "Parametric analysis of DFAL based dynamic comparator," ICTACT Journal on Microelectronics, vol. 3, pp. 354-358, 2017, doi: 10.21917/ijme.2017.062.

[23] B. P. Singh, M. Singh and S. K. Roy, "Mathematical Modeling of Electronic Devices and Circuits," AIP Conference Proceedings 1324, 2010, pp. 65-69, doi: 10.1063/1.3526268.

[24] C. Bruce and T. R. Brown, "Handbook of Operational Amplifier Applications," Texas Instruments: Application Report, 2016.

[25] J. Zhao, "Modeling and Simulation of Digital Filter," Proceedings of 4th National Conference on Electrical, Electronics and Computer Engineering, Xi'an, China, pp. 1333-1338, 2015.

\section{BIOGRAPHIES OF AUTHORS}

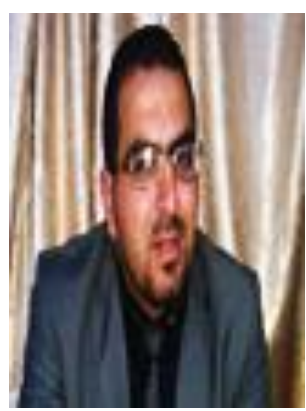

Mahmoud Al-Suod (iD I8I SC P is associate assistant professor in power and mechatronics department at Tafila Technical University from 2020-now, He is assistant professor in power and mechatronics department at Tafila Technical University from 2014-2020. Hereceived his $\mathrm{PhD}, \mathrm{MSc}$ and B.Sc in Electrical Engineering, Nattional University of shipbuilding adm. Makarav, in 2013, 2009, 2007. his research of interist the automation of electric power systems, information provision of electric power systems, control. He can be contacted at email: m.alsoud@yahoo.com. 

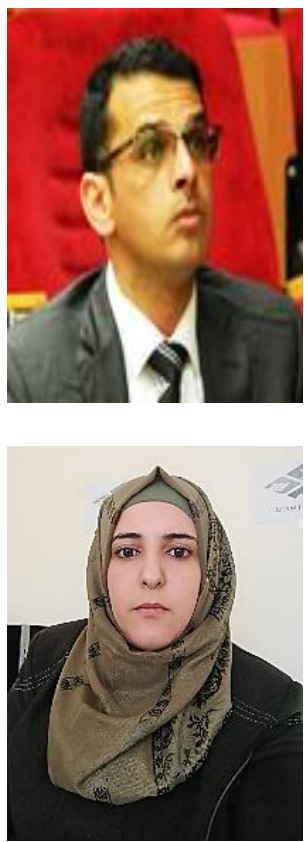

Alaa Al-Quteimat (iD $\mathrm{SI}$ SC $\mathrm{P}$ received the B.Sc. degree in electric power engineering from Tafila Technical University, Tafila, Jordan, in 2008, the M.Sc. degree in energy management engineering from the University of Jordan, Amman, Jordan, and the Ph.D. degree in electrical engineering from the Technical University of Berlin, Berlin, Germany in 2018. She is currently an assistant professor at the Tafila Technical University, Tafila, Jordan. Her research interests include control of power electronics applications in renewable energy, power system analysis, electric machines, and renewable energy conversion. She can be contacted at email: aalquteimat@gmail.com.

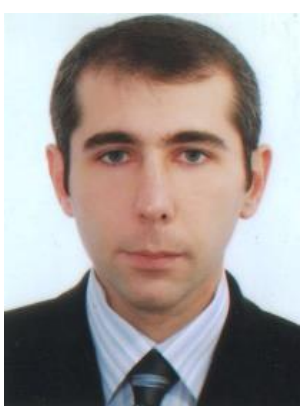

Oleksandr Ushkarenko (D) 8 SC $\mathrm{P}$ He received his Msc from Admiral Makarov National University of Shipbuilding, 2005, and his PhD from Kherson National Technical University, 2007. From 2005-2007: He was postgraduate. From 2007-2010: assistant professor. From 2010 - present: associate professor. His research of interest in microprocessor control system. He can be contacted at email: maestrotees@gmail.com. 